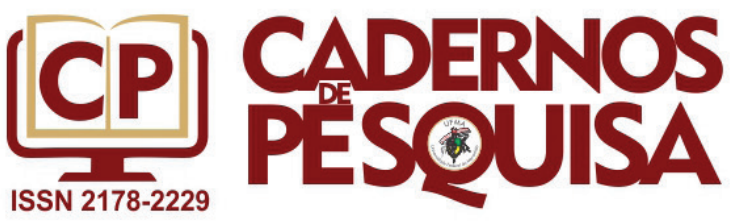

ISSN 2178-2229

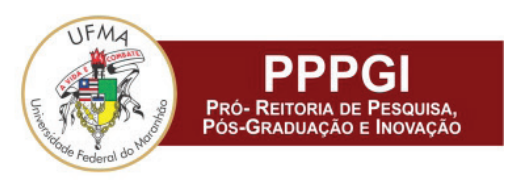

DOl: http://dx.doi.org/10.18764/2178-2229.v26n2p169-193

\title{
INTERCULTURALIDADE NA EDUCAÇÃO DE SURDOS EM 5 ANOS \\ DE PESQUISA NO BRASIL: pesquisa de revisão integrativa
}

\author{
INTERCULTURALITY IN DEAF EDUCATION IN 5 YEARS OF \\ RESEARCH IN BRAZIL: research on integrative literature review
}

\section{INTERCULTURALIDAD EN LA EDUCACIÓN DE SORDOS EN 5 AÑOS DE INVESTIGACIÓN EN BRASIL: investigación sobre revisión de literatura integradora}

\author{
Indiamaris Pereira \\ Mestranda em Educação. Bolsista da CAPES. \\ Docente no Instituto Federal de Ciência e Tecnologia de Santa Catarina. Itajaí - Santa Catarina \\ indiamaris.pereira@ifsc.edu.br \\ Paulo Roberto Sehnem \\ Doutor em Educação UNIVALI. Joinville - Santa Catarina \\ paulo@webespanhol.com
}

\section{Resumo}

Esse artigo apresenta os resultados de uma pesquisa de revisão integrativa de literatura, cujo objetivo geral foi mapear a produção científica brasileira atual em Programas de Pós-GraduaçãoStricto Sensu publicadas entre 2013 e 2017 sobre interculturalidade na educação de surdos. O corpusde análise se constituiu denove dissertações resgatadas no banco de dados da Coordenação de Aperfeiçoamento de Pessoal de Nível Superior (Capes). Pela articulaçãoda modalidade, ano, local, área do conhecimento, órgãos de fomento e perfil dos autores, das instituições de ensino e das produções, verificou-se tendência de crescimento em relação ao número de trabalhos ao longo dos últimos cinco anos. A região sul do país se destacou no número de produções. Pesquisas de abordagem puramente quantitativa não foram encontradas, dentre as pesquisas qualitativas destacaram-se a etnografia e o estudo de caso. Todas as pesquisas foram desenvolvidas em Programas de Pós-Graduação mantidos por instituições sem fins lucrativos. $O$ serviço público é o regime de contratação com mais pesquisadores. Duas pesquisas receberam fomento, advindo de instituições públicas eas temáticas fomentadas foram internacionalização e implante coclear. As temáticas mais exploradas foram a formação de professores e os aspectos do desenvolvimento linguístico.

Palavras-chave: Interculturalidade. Educação de Surdos. Revisão Sistemática.

\begin{abstract}
This article presents the results of an integrative literature review, whose general objective was to map the current Brazilian scientific production in Stricto Sensu Postgraduate Programs published between 2013 and 2017 About interculturality in the education of the deaf. The corpus of analysis consisted of nine dissertations retrieved in the database of the Coordenação de Aperfeiçoamento de Pessoal de Nível Superior (Capes). Through the articulation of the modality, year, place, area of knowledge, development agencies and profile of authors, educational institutions and production, there has been a tendency of growth in relation to the number of works over the last five years. The southern region of the country stood out in the number of productions. Researches of purely quantitative approach were not found, among the qualitative researches the ethnography and the case study were highlighted. All research was developed in Graduate Programs maintained by non-profit institutions. Public service is the hiring regime with more researchers. Two researches were promoted, coming from public institutions and the themes promoted were internationalization and cochlear implantation. The most explored themes were teacher training and aspects of language development.
\end{abstract}

Keywords: Interculturality; Deaf Education. Systematic Review.

Artigo recebido em novembro de 2018. Aprovado em maio de 2019. 


\section{Resumen}

este artículo presenta los resultados de una revisión de literatura integradora, cuyo objetivo general fue cartografiar la producción científica brasileña actual en los Programas de Postgrado Stricto Sensu publicados entre 2013 y 2017 sobre interculturalidad en la educación de sordos. El corpus de análisis consistió en nueve disertaciones recuperadas en la base de datos de la Coordenação de Aperfeiçoamento de Pessoal de Nível Superior (Capes). Por la articulación de la modalidad, año, lugar, área de conocimiento, agencias de desarrollo y perfil de autores, instituciones educativas y producción, se verificó una tendencia de crecimiento en relación con el número de trabajos en los últimos cinco años. La región sur del país se destacó en el número de producciones. No se encontraron investigaciones de enfoque puramente cuantitativo, entre las investigaciones cualitativas se destacaron la etnografía y el estudio de caso. Todas las investigaciones se desarrollaron en programas de posgrado mantenidos por instituciones sin fines de lucro. El servicio público es el régimen de contratación con más investigadores. Se promovieron dos investigaciones, provenientes de instituciones públicas, y los temas promovidos fueron la internacionalización y la implantación coclear. Los temas más explorados fueron la formación docente y aspectos del desarrollo lingüístico.

Palabras clave: interculturalidad; Educación de sordos. Revisión Sistemática.

\section{INTRODUÇÃO}

A gênese das pesquisas brasileiras relacionadas à temática educação e surdez esteve marcada pela corrente ouvicentrista. O termo ouvicentrismo e suas aproximações semânticas (ouvintismo, fonocentrismo, audismo) são descritos como uma ideologia dominante que constrange o surdo a simular-se como ouvinte para se adequar à sociedade, pois delimita que alguém é superior com base na capacidade de ouvir ou comportar-se da mesma maneira um ouvinte (BAUMAN; MURRAY, 2009; MACHADO; TEIXEIRA; GALASSO, 2017; OHNA, 2010)

Dentre os dispositivos mais poderosos na construção da imagem social dos povos colonizados está a literatura (FLEURI, 2014). O discurso científico exerce poder de legitimar a produção de ausências. Na década de 80 , período em que, de acordo os registros do catálogo de teses e dissertações da Coordenação de Aperfeiçoamento de Pessoal de Nível Superior (CAPES), se iniciam no Brasil pesquisas em nível stricto sensu dentro da temática educação e surdez, mais especificadamente a partir de 1987. Nesse início, foram registradas onze pesquisas, dentro da já referida temática educação e surdez, desses trabalhos, oito foram dissertações e três teses. Três das dissertações e todas as teses foram oriundas de PPG em Fonoaudiologia, apenas duas dissertações foram oriundas de PPG em Educação'.

Aprimeira pesquisa desenvolvida em nível stricto sensué uma dissertação defendida na Pontifícia Universidade Católica de São Paulo (PUC-SP) intitulada "A criança surda: educação para a marginalização"2 (TRENCHE, 1995). Esse estudo pretendeu questionar as instituições sociais legitimadas para intervir no processo de formação da criança com surdez. Conforme a autora, "[...] não dando conta das diferenças estabelecidas pela peculiaridade de sua condição fundamentam seus procedimentos na homogeneização do comportamento humano" (TRENCHE, 1995, p. 110). Contudo, vale ressaltar que além da investigação ter sido realizada em um PPG em Fonoaudiologia, cuja titulação concedida era mestre em distúrbios da comunicação, os materiais de análise foram produzidos durante um atendimento fonoaudiólogo. Tal pesquisa registrou evidências de intensos esforços dedicados a ensinar uma criança surda a utilizar a língua oral e a língua escrita com objetivo de possibilitar à criança adequar-se à sociedade.

Adequar-se, como evidenciado na pesquisa acima, significava tornar-se "menos surdo", "mais igual aos ouvintes", normalizar-se para pertencer a sociedade. A ausência das pessoas surdas nos espaços sociais foi intencionalmente forjada e teve o campo

\footnotetext{
Dados obtidos pela string de busca [educa* AND surd* AND libras]. As dissertações restantes foram: uma de PPG em Educação Especial, uma em PPG em Linguística e uma de PPG em Computação. Disponível em: <http://bit.ly/dfanos80>.

2 Durante a realização da presente pesquisa o texto completo dessa dissertação não estava disponível no site da CAPES. O trabalho completo, digitalizado, foi encontrado no sistema de publicação eletrônica de teses e dissertações da Universidade Federal de Uberlândia, disponível em: <http://www.nuteses.temp.ufu.br/tde_busca/processaPesquisa. php?pesqExecutada $=2 \&$ id $=855$ \&listaDetalhes[]=855\&processar=Processar>. $O$ trabalho completo também pode ser encontrado em: <http://bit.ly/trenche>.
} 
científico como legitimador, dado que a maneira tradicional de escrever sobre surdos foi focar no fato da condição de não ouvir e interpretar todos os outros aspectos de suas vidas como consequências desse fato (PADDEN; HUMPHRIES, 1988).

Registros dos discursos que delinearam as representações acerca da surdez nos últimos cem anos testemunham que a produção da ausência dessas pessoas foi mediada ora pela caridade, ora pela violência (SILVA, L., 2011; SKLIAR, 2013). A ausência à qual os surdos foram submetidos é produto de uma ação intencional vinculada ao modelo de racionalidade ocidental. Nesse modelo, conforme Santos (2002, p. 247), "[...] tudo o que o cânone não legitima ou reconhece é declarado inexistente." Um dos resultados da produção destas ausências é o desperdício da experiência social.

Diferentes movimentos sociais buscam resistir a esse desperdício e desconstruir a lógica da colonialidade imposta a população mundial nos mais variados espaços sociais. No contexto da sociedade globalizada, a noção de interculturalidade "[...] mais do que uma atitude de comiseração e solidariedade para com o outro, implica uma revisão radical das perspectivas socioculturais, políticas e epistemológicas que mobilizam a interação com o outro" (FLEURI, 2014, p. 12).

A perspectiva intercultural interessa aos envolvidos com a educação de surdos porque pressupõe um intercâmbio cultural sem hierarquização dos sujeitos envolvidos. Nesse sentido, e tendo em vista o pressuposto de que o discurso científico proferido no espaço acadêmico tem poder de legitimar as argumentações emergentes no âmbito educacional, sublinhou-se, dentre as diversas questões possíveis de serem tratadas, a importância das investigações em torno da temática interculturalidade na educação dos surdos.

A pesquisa prévia de trabalhos científicos é uma etapa fundamental para conhecer o que já foi produzido e o que ainda pode ser estudado relacionado a determinadas temáticas de interesse. O processo de revisão sistemática da literatura é definido como uma metodologia de pesquisa com rigor científico e de grande transparência cujo objetivo passa por garantir a qualidade das fontes (FARIA, 2016; FELIZARDO et al., 2017). Trata-se, portanto, de uma metodologia confiável que de acordo com Gough, Thomas e Oliver (2012) pode ser considerada um marco em um momento decisivo na história da ciência.

Na mesma esteira, Faria (2016) considera oportuno aplicar às Ciências da Educação tal metodologia alegando que no campo da educação os referenciais teóricos pouco avançaram nas últimas três décadas. As pesquisas de RSL possibilitam refletir entre o conhecimento real e o assumido e diferenciam-se das revisões bibliográficas tradicionais e das revisões narrativas porque a credibilidade da RSL é proporcional à possibilidade de replicação do processo por um outro indivíduo (GOUGH; THOMAS; OLIVER, 2012; LADYMAN, 2002; PEREIRA, 2017; SAUR-AMARAL, 2011; TRANFIEL, DENYER, SMART; 2003 TRANFIELD; MOUCHEL, 2002).

Se a frequente avaliação do que vem sendo pesquisado nas diversas áreas do conhecimento é de grande importância, tal atividade merece destaque no que se referem aos PPG, visto que esses são espaços privilegiados para o desenvolvimento da ciência no Brasil (GAMBOA, 2012). Pesquisas de RSL com o objetivo de mapear os trabalhos sobre a educação de surdos ainda são pouco realizadas no Brasil. A maior parte dos trabalhos encontrados com abordagens sistemáticas de revisão de literatura no campo das Ciências da Educação se articulam ao campo das Ciências da Saúde e, mais recentemente, da tecnologia digital (LEITE, 2018; MELO; GOMES, 2013; FERREIRA; NASCIMENTO; PITANGA, 2014).

Estudos de revisões sistemáticas de literatura no campo da educação de surdos foram encontrados referentes ao processo de ensino e aprendizagem de matemática e química para alunos surdos (DESSBESEL; SILVA; SHIMAZAKI, 2018; VERTUAN; SANTOS, 2019), à formação de professores para a educação de surdos (MUTTÃO; LODI, 2018) e à inclusão de alunos surdocegos (BRANCO; LEAL, 2018). Também 
foram encontrados estudos que articulavam ensino da Língua Brasileira de Sinais (Libras) e Português ao uso de Tecnologias Digitais (TD) (CORRÊA et al., 2018; COUTINHO; CARVALHO, 2016; CARVALHO; CAVALCANTI; SILVA; 2019; ROCHA; LIMA; QUEIROZ, 2018; MELO; GOMES, 2013).

No que tange a interculturalidade na educação de surdos, não foram resgatados estudos que mapeassem de forma sistemática o que foi produzido nas pesquisas nacionais desse campo. Sendo essa a atual fronteira do conhecimento, referenda-se a pertinência do presente estudo sistemático de revisão integrativa da literatura cinzenta (dissertações e teses) brasileira, esse recorte justifica-se com base na capacidade analítica da equipe que pesquisa.

$\mathrm{Na}$ presente pesquisa, o termo integrativo diz está precisamente aplicado à integração de opiniões, conceitos ou ideias provenientes das pesquisas selecionadas (WHITTEMORE; KNAFL, 2005). As pesquisas de revisão integrativa possibilitam sistematização do conhecimento científico. Em outras palavras, contribuem para a organização de um pequeno pedaço do caos acadêmico. Conforme Botelho, Cunha e Macedo (2011, p. 133) o método da revisão integrativa pode ser "incorporado às pesquisas realizadas em outras áreas do saber, além das áreas da saúde e da educação."

Nessa pesquisa questiona-se: o que e como tem sido pesquisado, na atualidade, em nível stricto sensu, abordando a temática interculturalidade na educação dos surdos? Como questões articuladas emergem: Quais são as instituições e Programas de Pós Graduação (PPG) que têm se interessado por esta discussão? Em quais modalidades estas pesquisas têm acontecido? Qual o perfil dos pesquisadores? O que discutem essas pesquisas? Quais metodologias aplicadas? Com quais objetivos? Existe fomento para essas pesquisas? Qual? Por qual instituição?

Para responder a essas perguntas foi elencado o objetivo geral de mapear a produção científica nacional atual, de nível stricto sensu, sobre interculturalidade e educação de surdos. Para bem atingir o objetivo referido, analisou-sedados como: modalidade, ano, local, área do conhecimento órgãos de fomento e perfil geral dos autores, das instituições de ensino, e das produções.

O estudo está organizado em cinco sessões. Após as considerações já introduzidas apresenta-se a fundamentação teórica e, em seguida, a descrição dos caminhos metodológicos percorridos. Na terceira seção, declaram-se os resultados obtidos acrescidos de apontamentos analíticos. Finda-se o presente estudo com algumas considerações elencadas pelos autores.

\section{FUNDAMENTAÇÃO TEÓRICA}

No mundo ocidental as mudanças no perfil das pesquisas acadêmicas sobre surdez pela perspectiva cultural começam a melhor se delinear na década de 70 . Em 1978, foi criado na Universidade de Bristol (Reino Unido) o Deaf Studies Centre (Centro de Estudos Surdos) que inaugurou um novo espaço acadêmico de discussão sobre as questões relacionadas à comunidade surda na perspectiva sócio-cultural e linguística: Deaf Studies (Estudos Surdos). Com pesquisas que sustentavam o direito do surdo à sua língua e à sua cultura, os Deaf Studies se consolidaram na década de 80 a partir de dois programas estadunidenses que concentraram a produção desse campo: um na Boston University, em 1981, e o outro na California State University, em 1983 (BAUMAN, 1995, 2002; BAUMAN; DRAKE, 1997; BAUMAN; MURRAY, 2009, 2010).

No Brasil, em meados da década de 90, emergem os Estudos Surdos em Educação, tendo como origem os Estudos Surdos, cujo escopo se situava dentre os Estudos Culturais. As pesquisas com base nessa linha problematizavam a surdez pela perspectiva sócioantropológica. Com isso, os estudos que discutiam a surdez a partir da diferença e do reconhecimento político começaram a ganhar mais espaçono campo acadêmico e um novo discurso sobre surdez passa a ser gerado por investigações que problematizam surdez dentro de uma nova perspectiva culturalista (SKLIAR, 2013). 
Para Strobel (2015), cultura surda é a forma como os sujeitos surdos entendem o mundo e o modificam para o tornar mais acessível e habitável; também se refere aos comportamentos, valores, regras e crenças, que envolvem as comunidades surdas. Para estudiosos do campo dos Estudos Surdosos conceitos de cultura e identidade surda são extremamente importantes, mas nem sempre são rigorosamente abordados. Nesse seguimento, Kusters e Friedner (2015, p. 19, tradução nossa) advertem que:

\footnotetext{
[...] esses conceitos são muitas vezes adotados sem crítica como ideologias e não como conceitos de enquadramento, como se houvesse uma maneira de ter uma "identidade surda" e como se houvesse uma cultura surda no mundo. De fato, esses conceitos são frequentemente tomados como garantidos e tanto os estudiosos quanto os leigos costumam mencionar a "cultura Surda" sem qualificar exatamente a cultura Surda ou onde ela existe, assumindo que a identidade surda ou cultura surda é universal.
}

Pela noção de "cultura surda", no singular, se corre o risco de difundir um modelo único de experiência para todos os surdos, que Wrigley (1996) designou como uma "nova arrogância". Outrossim, Branson e Miller (2002, p. 243, tradução nossa) consideram que a ideia de todos os surdos terem uma única identidade é "[...] uma nova violência simbólica associada não à condenação da diferença, mas à negação da diferença", ou seja, um novo imperialismo cultural, ainda que inconsciente e não reconhecido. Atualmente pesquisadores têm examinado como as definições da cultura surda surgiram, a quem elas excluem e se as definições baseadas em outros conceitos podem ser menos exclusivas e, até mesmo, epistemologicamente mais úteis (KUSTERS, 2012; YOUNG; TEMPLE, 2014).

Fleuri (2003) elucida que a possibilidade de respeitar as diferenças e de integrálas em uma unidade que não as anule é um grande desafio, essa proposição vai ao encontro da proposta de multiculturalismo de Sá (2006) para quem o multiculturalismo pressupõe um intercâmbio cultural, no qual não apenas ouvintes e surdos possam interagir e mutuamente se enriquecer, mas se trata de uma proposta em que outras culturas também possam ser ressaltadas.

Para Ladd (2006), as tensões entre o comum e o diverso derivam do status multiculturalinerente à participação e interação dos povos usuários de línguas de sinais, tanto em nível nacional quanto internacional. A multiplicação de vias de contato cultural e transnacional (físico e/ou virtual) entre as comunidades surdas e o crescimento do número de pessoas ouvintes que aprendem e usam línguas de sinais, são pontuadas como mudanças vivenciadas pelos surdos que revelam a emergência em olhar além dos conceitos e estruturas já estabelecidos para possibilitar que novas reflexões sucedam (KUSTERS; De MEULDER; O'BRIEN, 2017; O'BRIEN; STEAD; NOURSE, 2017).

$\mathrm{Na}$ esteira das novas reflexões, a educação de surdos tem se tornado um tema de múltiplas dimensões, dentre elas se encontra destacada a dimensão multicultural. As instituições de ensino comuns ou bilíngues, espaços educativos que acomodam maior parte dos estudantes surdos, podem ser concebidas como essencialmente multiculturais, visto que, grosso modo, abrigam dois grupos culturalmente diferentes: surdos e ouvintes. Porém, como já apontado, pela concepção de culturas surdas, no plural, amplifica-se a noção de contato cultural propiciando a ponderação de quemesmo os espaços sociais ocupados apenas por sujeitos surdos podem ser caracterizados como multiculturais (KUSTERS; De MEULDER; O'BRIEN, 2017).

Ao longo dos anos 1960 a 1990, estudiosos europeus não reconheciam a palavra intercultural e empregavam, no geral, o termo multiculturalismo. A academia anglófona, há quase meio século, assumiu a liderança na teorização e na formulação de políticas de multiculturalismo e, portanto, tal termo se tornou popular. Já o termo "intercultural" ganhou espaço após seu uso em documentos oficiais transnacionais, por exemplo, os produzidos pelo Conselho da Europa e pela Comissão Europeia. No entanto, isso não significa que seu uso seja consensual, seja na interpretação científica ou em termos 
ideológicos. Embora a palavra intercultural ainda seja considerada um neologismo nos círculos anglófonos, ela tem sido aceita como lugar comum em pesquisas nos círculos ibero-americanos (BENNETT, J., 2015).

Se para Bennett J. (2015, p. 672), "Infelizmente, como o pluralismo, a diversidade e o multiculturalismo tornaram-se significantes flutuantes com inúmeros significados", para Fleuri (2014, p. 90) é na diversidade de propostas e perspectivas que reside a potencia de criação e reflexão dos debates, para ela a riqueza "[...] consiste justamente na multiplicidade de perspectivas que interagem e que não podem ser reduzidas por um único código e um único esquema a ser proposto como modelo transferível universalmente."

No Brasil, a terminologia "multiculturalismo" tem sido problematizada e revista. O termo interculturalidade tem sido apresentado como uma abordagem atualizada a respeito da interação cultural. Essa abordagem é orientanda pela construção de uma sociedade plural, democrática e eminentemente humana capaz de articular políticas de igualdade e identidade, pois as culturas diferentes são entendidas como contextos complexos cuja relação produz confrontos (COPPETE, 2012).

No campo da educação a noção de interculturalidade proporciona condições para o fortalecimento da identidade cultural e estimula a aquisição do conhecimento cultural de outros povos. Para Silva T. (2009, p. 41-42) isto significa que não houve somente uma transição de termos conceituais mas, sim "[...] uma mudança no tratamento da pluriculturalidade no espaço da escola. Das preocupações marcadamente lingüísticas, características da educação bicultural e bilingüe [sic], a interculturalidade considera o contexto sociocultural dos alunos."

Naesteira das teorizações ibero-americanas, na presente pesquisa multiculturalismo será entendido como constatação da constituição pluricultural do espaço escolar; já por interculturalidade, será adotado a noção de uma postura crítica de respeito e cuidado com o Outro que favorece a construção de um projeto de colonial, mediante o qual é possível integrar dialeticamente as diferenças (WALSH, 2012).

\section{PROCEDIMENTOS}

O processo de pesquisa seguiu sete etapas previamente definidas e absolutamente respeitadas na sua execução, quais sejam: i) construção de um protocolo de revisão sistemática de literatura (PRSL); ii) definição da pergunta; iii) extração dos estudos; iv) seleção dos estudos; v) avaliação crítica; vi) coleta dos dados e vii) síntese dos dados. Nessa revisão integrativa seguiu-se as orientações fornecidas por Ramos, Faria e Faria (2014) buscando obter máximo de rigor na seleção e análise dos dados.

O banco de dados selecionado para extração dos trabalhos acadêmicos foi o banco de teses e dissertações da Capes. Essa escolha se deu devido à proposta de organização e validação dos dados de trabalhos acadêmicos disponibilizados na plataforma.

Para contribuir com a comunidade acadêmica interessada, disponibilizou-se os dados brutos obtidos em cada etapa através de links de acesso aos documentos gerados; dessa forma possibilita-se que outras análises possam ser feitas a partir dos mesmos dados sem necessidade de repetir a coleta e também torna todo o processo transparente, replicável e auditável. Os links serão apresentados entre os símbolos matemáticos menor maior <>. O protocolo de revisão sistemática de literatura definido para esta pesquisa está disponível em detalhes e pode ser acessado pelo link <http:// bit.ly/protocolorsl>. As equações de busca modeladas para esta pesquisas serão apresentadas, exatamente como foram aplicadas, entre colchetes [ ], ou seja, todo conteúdo dentro dos colchetes faz parte da equação.

O recorte temporal foi de 2013 a 2017; a escolha por este período se justifica pela busca ser de um mapeamento atual. Justifica-se também pelo fato de que a extração 
e a análise ocorreram ao longo do ano de 2017, mas foram atualizadas em setembro de 2018, as plataformas da Capes são atualizados em abril referentes aos trabalhos do ano anterior, logo trabalhos reportados depois dessa data não estão incluídos neste estudo.

A extração dos estudos aconteceu durante o ano de 2017 e foi atualizada nos três primeiros dias do mês de setembro de 2018, sempre de acordo com as equações de pesquisa definidas no PRSL. As palavras chave selecionadas foram: educação, surdez, interculturalidade e multiculturalismo, com essa base, a equação de busca aplicada para extração foi: [(intercultural* OR multicultural*) AND (educa* AND surd*)], o termo multicultural foi adicionado a equação a fim de aferir possíveis equivalências semânticas, dessa etapa 52 (cinquenta e dois) trabalhos foram extraídos. Os dados brutos referentes às produções podem ser acessados pelo link <http://bit.ly/_extraido>. Para seleção dos estudos a serem avaliados os critérios de inclusão aplicados foram: a) serem teses ou dissertações; b) publicados de 2013 até 2017; c) publicados no banco de dados da Capes; d) conter abstract; e) publicados em português, inglês, espanhol ou francês; f) ter escopo dentro do âmbito educacional. Abaixo apresenta-se o fluxograma das etapas de extração e seleção de dados:

Quadro 1 - Fluxograma do processo de extração e seleção.

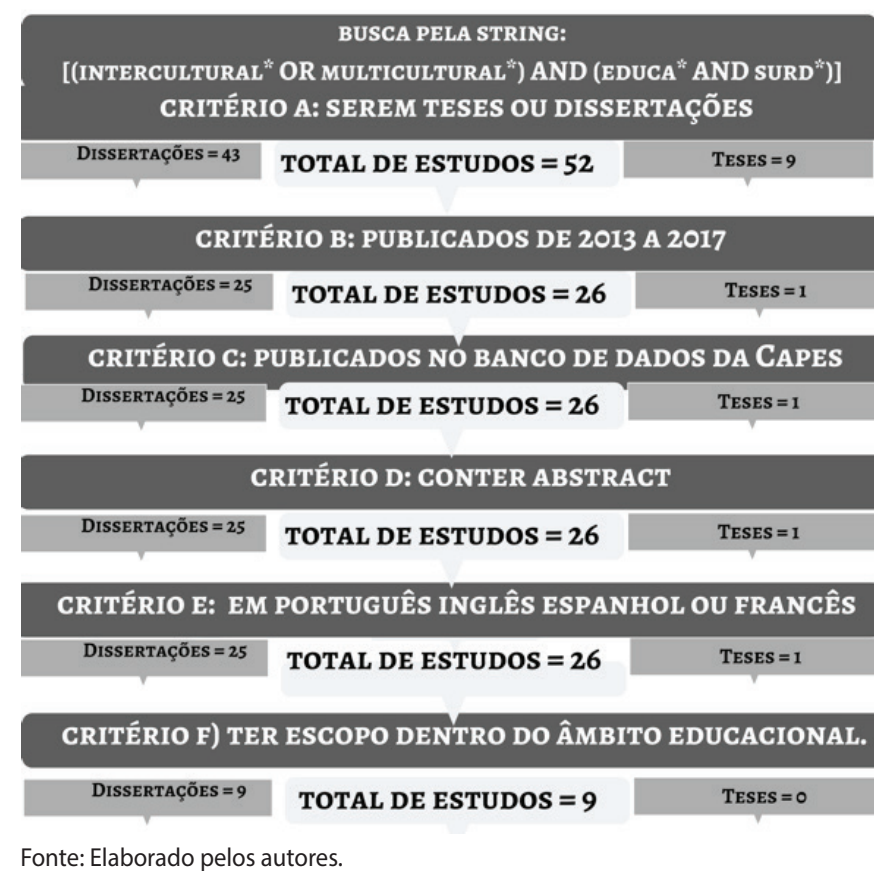

Após leitura flutuante dos títulos e dos resumos, nessa etapa 9 (nove) trabalhos foram selecionados. A avaliação crítica guiou-se pela perguntacentral da pesquisa e pelas perguntas articuladas, bem como teve o objetivo geral da pesquisa como balizador das avaliações.

Acoleta dos dados dos trabalhos selecionados guiou-se por 8 objetivos operacionais: i) caracterizar as produções através das modalidades em que os trabalhos têm sido produzidos; ii) identificar a distribuição temporal; iii) delinear quais são as instituições e PPG que têm se envolvido nas pesquisas; iv) delinear qual é o perfil dessas instituições; v) delinear o perfil geral dos pesquisadores que se engajaram em pesquisas dentro dessa temática; vi) identificar as temáticas e métodos aplicados; vii) aferir a existência de fomento; viii) caracterizar o fomento (agência / região / áreas temáticas dos trabalhos fomentados/ região dos PPG).

Adotou-se como critérios de validade metodológica a verificação e apreciação do protocolo por uma pesquisadora externa. A realização de cada etapa do processo ocorreu por dois pesquisadores e os dados foram confrontados ao término de cada etapa. O acompanhamento do processo também ocorreu por um pesquisador externo a 
área de pesquisa, bem como a apreciação foi levada ao grupo de pesquisa em que os pesquisadores estão cadastrados.

\subsection{Procedimentos para coleta dos dados de comparação}

Para complementar a pesquisa e contrastar os achados sobre as pesquisas dentro da temática interculturalidade na educação de surdos com o contexto global das pesquisas a respeito da interculturalidade, realizou-se outras quatro buscas breves e mais amplas, no mesmo banco de dados. Para melhor operacionalização, foi dado uma letra para cada busca (ES, X, Y, Z e K).

Para compreender o contexto global das pesquisas sobre interculturalidade, realizou-se a busca $X$, mais ampla, pela equação [intercultural ${ }^{*}$ OR multicultural ${ }^{\star}$ ], derivativo dessa busca são todos os trabalhos, de todas as áreas, que tiveram alguma conexão com a interculturalidade. Em seguida, efetuou-se a busca Y, um pouco mais restritiva, a fim de levantar dados gerais a respeito das pesquisas sobre interculturalidade apenas no campo educacional, essa segunda busca ocorreu pela equação[educa* AND (intercultural* OR multicultural ${ }^{*}$ )]; dessa busca, extraiu-se todos os trabalhos que relacionaram de alguma forma educação e interculturalidade.

Todos os trabalhos dentro do universo do contexto educacional (busca $Y$ ) estão contidos no grupo de trabalhos do contexto global (busca X), por fim, se executou uma busca Z, mais restritiva, com a equação [(intercultural ${ }^{*}$ OR multicultural ${ }^{*}$ ) NOT (educa*)]; essa busca deu condições de verificar os dados apenas das pesquisas sobre interculturalidade fora do contexto educacional. Para obter dados a respeito das pesquisas que relacionaram educação interculturalidade e internacionalização realizou uma última busca $(K)$ pela string [(multicultural ${ }^{*}$ OR intercultural $\left.{ }^{*}\right)$ AND internacional* ${ }^{*}$. A figura a seguir ilustra melhor essa contextualização e a relação geral entre as variáveis:

Figura 1 - Funil do gráfico de Venn básico: contexto das pesquisas sobre interculturalidade.

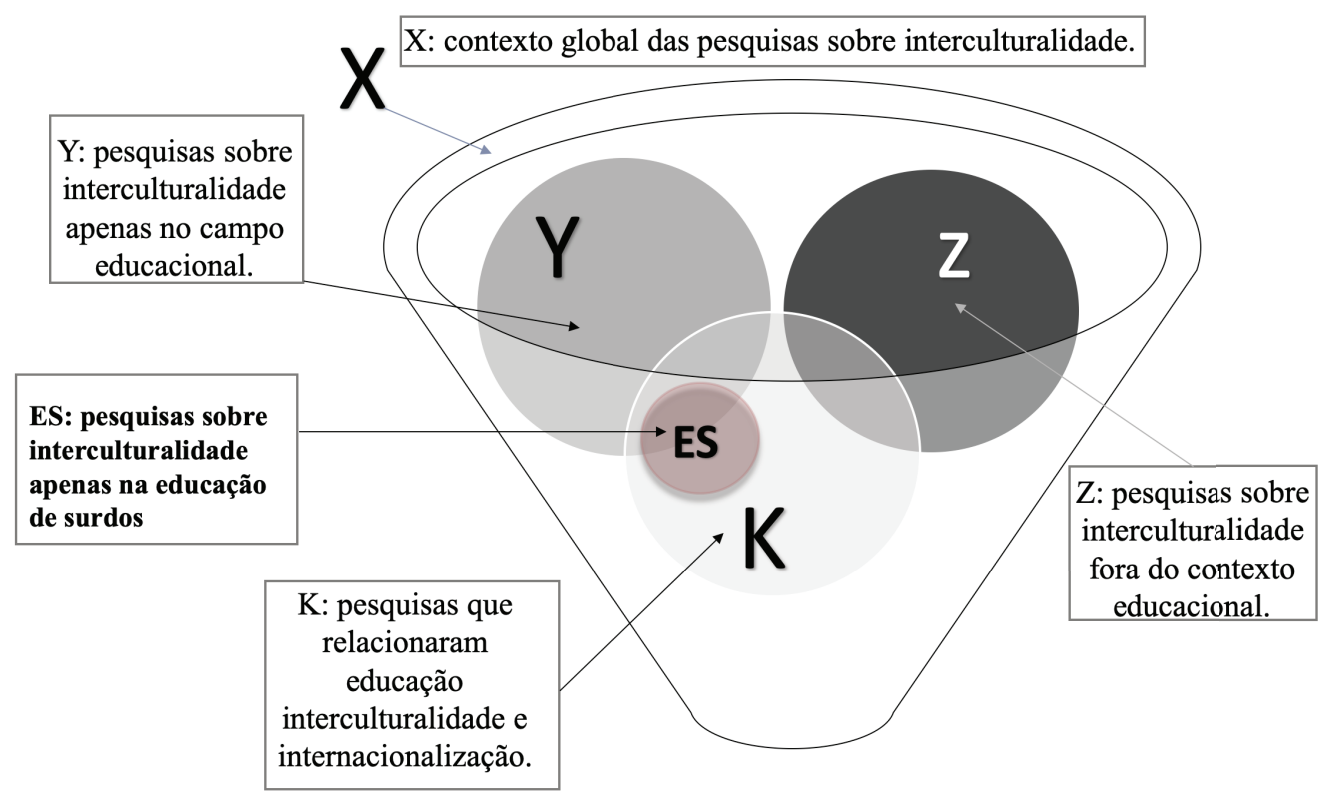

Fonte: Elaborada pelos autores.

\section{RESULTADOS E DISCUSSÃO}

O quadro abaixo contém o título de cada uma das nove pesquisas sobre interculturalidade na educação de surdos que foram selecionadas: 
Quadro 2 - Matriz de Síntese das pesquisas selecionados para o estudo.

\begin{tabular}{|c|l|}
\hline Cod & Títulos da Pesquisas \\
\hline A & Formação docente e educação de surdos: um encontro com a diferença, cultura e identidade surda. \\
\hline B & $\begin{array}{l}\text { Educação intercultural bilíngue para surdos: formação de professores para um ensino culturalmente sensível/ } \\
\text { relevante. }\end{array}$ \\
\hline C & $\begin{array}{l}\text { O desenvolvimento da competência comunicativa intercultural de surdos aprendizes de inglês: a internet como } \\
\text { meio }\end{array}$ \\
\hline D & Perceber, pensar e falar: o implante coclear na realidade escolar. \\
\hline E & A educação de surdos pelos estágios do processo de internacionalização do currículo. \\
\hline F & Tradução de música \& educação de surdos. \\
\hline G & Interações interculturais no contexto de ensino de libras como L2 na creche. \\
\hline H & $\begin{array}{l}\text { O direito à libras como língua materna: um estudo sobre a política educacional de educação infantil para crianças } \\
\text { surdas na rede municipal de ensino de Curitiba. }\end{array}$ \\
\hline I & O professor intérprete de libras em uma escola polo de Nova lguaçu. \\
\hline
\end{tabular}

Fonte: Elaborado pelos autores.

\subsection{As tendências das pesquisas}

A análise das modalidades pode servir de indício para avaliar a maturidade e o aprofundamento dos estudos em um dado campo. Dos estudos selecionados, no que se refere a essa categoria, observou-se que a única modalidade em que os trabalhos têm foram produzidos é dissertação de mestrado. Não se encontrou teses de doutorado nessa coleta. É sabido que trabalhos acadêmicos Stricto Sensu, como dissertações e teses, não se diferenciam por quantidade de páginas e sim pelo ineditismo. As teses que devem apresentar defesas inéditas oriundas de profunda investigação, representam um avanço para os estudos do campo em questão (DRUMMOND, 2003). Embora qualquer trabalho de investigação científica seja uma contribuição imensurável ao conhecimento e a evolução dos saberes, as teses favorecem os olhares ao novo e encorajam a ousadia. É amplamente sabido que a escrita de uma tese é um exercício que demanda recursos, tempo e criatividade.

Outra análise que feita sobre as tendências é a referente ao ano em que esses trabalhos são publicados ou, no caso das dissertações, defendidas. Durante o período recortado para essa investigação, observa-se crescimento das produções, o ano de 2017 se destaca como um dado animador.

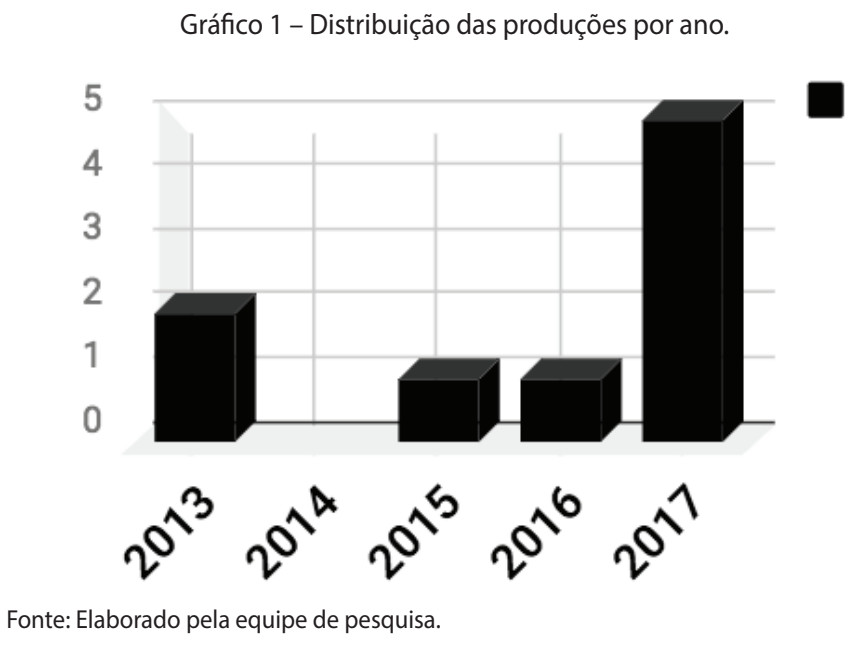

O aumento das publicações, que dobrou em tal período, é um indicativo de uma nova realidade no campo das pesquisas sobre interculturalidade na educação de surdos. A cronologia pode se relacionar ao surgimento de novas questões dentro das pesquisas no âmbito educacional, utilização de novas bases teóricas ou mesmo de situações sociais que emergem despertando novos interesses de investigação. Apresentam-se abaixo esses dados relacionados: 


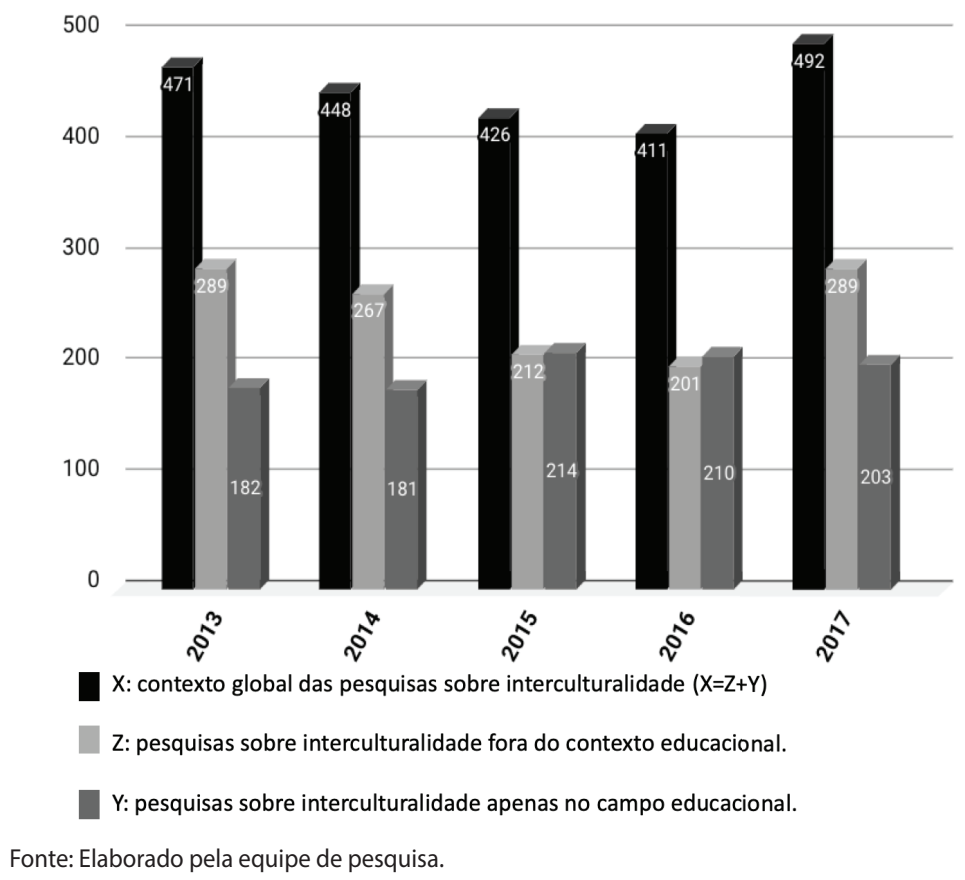

Sobre a quantidade dos trabalhos nos anos acima mencionados, é possível apreender que, embora o contexto geral dos trabalhos que discutem de alguma forma interculturalidade esteja em crescimento, quando extraídos do universo do contexto geral os trabalhos focados no campo educacional têm-se nos anos de 2013 e 2014 uma diferença em relação a quantidade, na qual as pesquisa dentro do campo educacional se sobressaem, apesar dessa diferença, verifica-se um decréscimo de aproximadamente 20,6\% entre 2014 e 2015, com estagnação em 2015 e 2016; entre 2016 e 2017 os dados são mais empolgantes, com aumento de $43,8 \%$.

O aumento de pesquisas no campo da internacionalização, impulsionada pelo forte processo de globalização e pelo aumento dos investimentos, que é apresentada por diversos autores como infusão de perspectivas interculturais a educação superior (LEASK, 2015), pode ter contribuído para este aumento. De acordo com o relatório do Plano Nacional de Pós-Graduação (2011-2020), a temática da internacionalização evoluiu acima das expectativas. Em termos de investimentos ultrapassouvalores de aproximadamente 100 milhões de reais em 2010 para900 milhões de reais em 2012.

A observação do contexto geral das pesquisas ao extrair-se as pesquisas focadas no campo educacional evidencia a constância de publicações, tal dado pode ser um indicativo positivo que mostra o atravessamento das discussões sobre interculturalidade para outros espaços.

Gráfico 3 - Forma da distribuição das produções por ano.

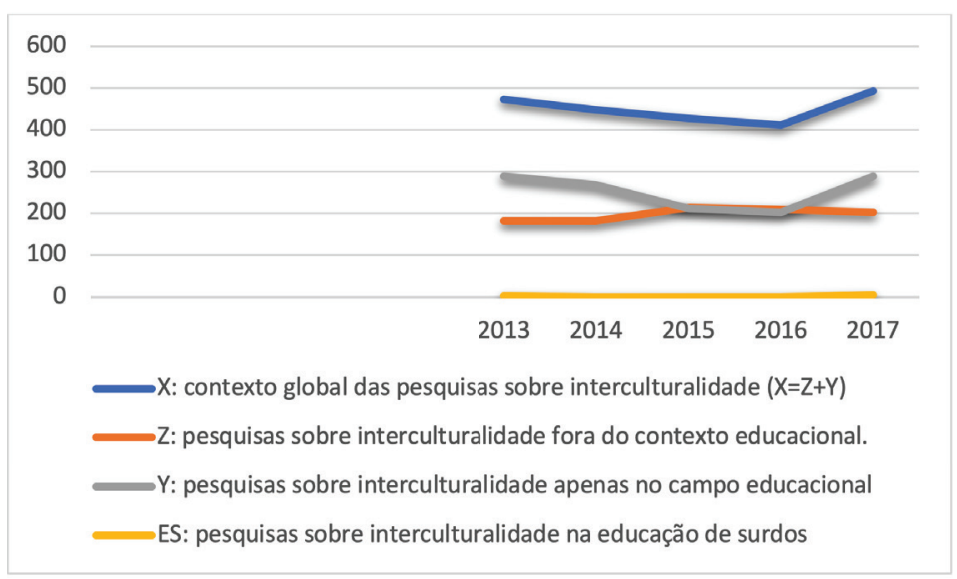

Fonte: Elaborado pela equipe de pesquisa. 
Retomando o crescimento do número de pesquisas sobre internacionalização, importa lembrar que a interculturalidade pode ser abordada com intenções veladas de homogeneização. O baixo número de pesquisas encontradas quando a discussão está centrada na educação de surdos quando comparado com este universo maior de pesquisas em outras temáticas pode ser revelador dos reais interesses no campo.

Relacionado os dados dos três contextos com os dados específicos obtidos por esta pesquisa pode-se constatar que, apesar da diferença no número de pesquisas, a curva de desenvolvimento quantitativo dos achados da presente pesquisa parece estar alinhado a curva número geral dos trabalhos desenvolvidos dentro do contexto educacional, conformeeobjetivado na breve análise quanto a forma do gráfico acima.

\subsection{Instituições e PPG das pesquisas}

Detectou-se que sete instituições de ensino foram responsáveis pela produção das dissertações. Destaca-se a Universidade Federal de Rondônia e a Universidade Federal do Rio de Janeiro como instituições com número maior de trabalhos.

Gráfico 4 - Instituições.

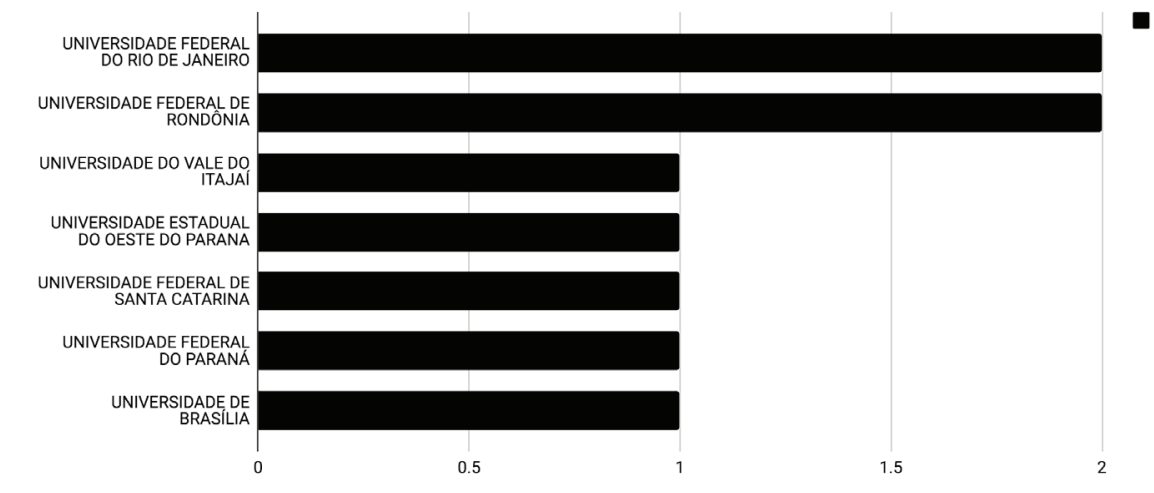

Fonte: Elaborado pela equipe de pesquisa.

Pela identificação das instituições foi possível mapear os estados e as regiões em que elas se encontravam. Essa é uma das características que delineiam o perfil das instituições e também revela em quais lugares há maior quantidade de pesquisas. A compreensão deste dado possibilita pensar sobre a contribuição destas regiões na produção e sistematização de novos conhecimentos.

Gráfico 5 - Estados X Regiões.
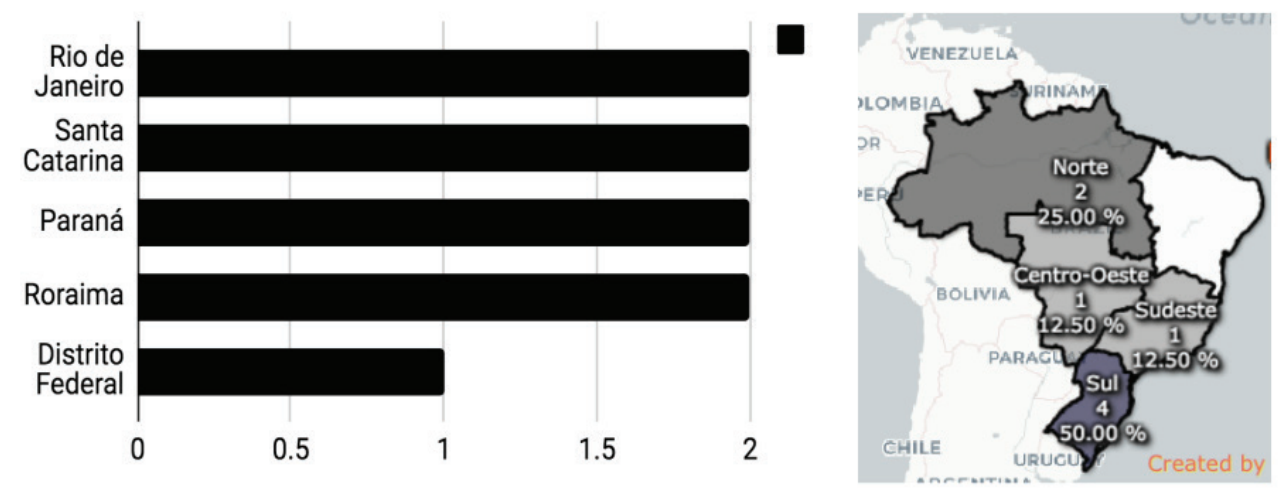

Fonte: Elaborado pela equipe de pesquisa.

De acordo com dados da Capes, a região que mais possui PPG é o Sudeste. O Sul é a segunda região que mais possuiu PPG no Brasil, apesar de estar em terceiro lugar, e o Nordeste não se destacou. O destaque dado ao sul do país no número de produções pode ser devido à tradição dessa região em desenvolvimento de pesquisas na área da educação de surdos. É lá que se iniciam os grupos pesquisas em nível de Pós-Graduação dentro do campo dos Estudos Surdos em Educação. 
Importa lembrar que este dado tem relação com as assimetrias na distribuição regional dos PPG. As assimetrias existentes no sistema de pós-graduação brasileiro têm sido apontadas em diversos vários documentos, e sido contemplada nos planos nacionais para o seu desenvolvimento. Face à existência de um quadro de assimetrias - Plano Nacional de por Graduação apresenta preocupações com o combate a esse fenômeno. No documento, otema é considerado importante para o país e o combate às assimetrias é tomado como uma temática cuja complexidade irá exigir a ação sinérgica de vários órgãos do governo (PNPG, 2011-2020).

Ainda sobre as temáticas relacionadas à produção de conhecimento científico no campo da surdez, o estado de Santa Catarina sedia o único Campus de Educação Científica e Tecnológica da América Latina, foi pioneiro no curso de Letras Libras (licenciatura e bacharelado).

Até a atualidade, o Rio de Janeiro abriga uma das, se não a, instituições de ensino mais importante para história da educação dos surdos no Brasil, o Instituto Nacional de Educação de Surdos (INES). Foi também esse estado que recebeu, no século IX, o grande defensor e difusor da comunicação gestual entre surdos, o professor Ernest Huet (LOPES; VEIGA-NETO, 2017).

Para delinear qual é o perfil dessas instituições, tambémse aferiu os níveis em que elas se classificam nas categorias administrativas. Na categorização das instituições de Ensino Superior como pública ou privada tomou-se por base o artigo 19 da Lei $n^{\circ}$ 9.394, de 20 de dezembro de 1996, a Lei de Diretrizes e Bases da Educação Nacional - LDB, atualizada até março de 2017: "I - públicas, assim entendidas as criadas ou incorporadas, mantidas e administradas pelo Poder Público; II - privadas, assim entendidas as mantidas e administradas por pessoas físicas ou jurídicas de direito privado" (LDB, 2017). filantrópica:

O próximo gráfico revela os dados relacionados a categorização confessional e Gráfico 6 - Categorias Administrativas das Instituições.

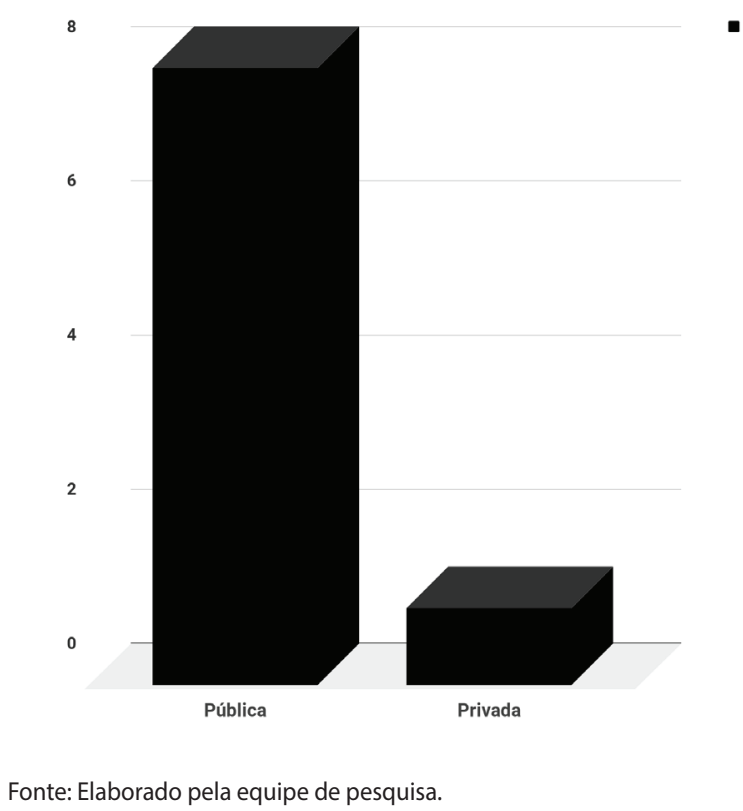

Com base na mesma lei, para além das categorias administrativas, as instituições de ensino ainda se enquadram em mais quatro categorias: particular, comunitária, confessional e filantrópica. A respeito dessa classificação, destaca-se o artigo 20:

I - particulares em sentido estrito, assim entendidas as que são instituídas e mantidas por uma ou mais pessoas físicas ou jurídicas de direito privado que não apresentem as características dos incisos abaixo; II - comunitárias, assim entendidas as que 
são instituídas por grupos de pessoas físicas ou por uma ou mais pessoas jurídicas, inclusive cooperativas educacionais, sem fins lucrativos, que incluam na sua entidade mantenedora representantes da comunidade; III - confessionais, assim entendidas as que são instituídas por grupos de pessoas físicas ou por uma ou mais pessoas jurídicas que atendem a orientação confessional e ideologia específicas e ao disposto no inciso anterior; IV - filantrópicas, na forma da lei. (LDB, 2017, p. 22).

Verificou-se que a instituição privada Universidade do Vale do Itajaí é comunitária. Considerando que as universidades comunitárias são instituições são prestadoras de serviços públicos, de interesse coletivo, sem fins lucrativos (MOROSINI; FRANCO, 2004). Aponta-se que todas as pesquisas foram desenvolvidas em PPG mantidos por instituições sem fins lucrativos. Torna-se visível a importância dessas instituições para o desenvolvimento deste campo.

O acentuado número de produções nos PPG em Educação não é um dado surpreendente, uma vez que este estudo toma porrecorte o âmbito educacional, embora nem todo tema de pesquisa que toma por escopo a educação ou a educação de surdos têm suas produções oriundas de PPG neste campo, como já evidenciado no início das pesquisas sobre educação de surdos no Brasil.

É interessante, então, de sobremaneira aferir em quais outros PPGco-ocorre o interesse por esta temática.

Gráfico 7 - Programas de Pós-Graduação.

Fonte: Elaborado pela equipe de pesquisa.

Achados de outras pesquisas corroboram com nossos dados. A pesquisa recente de Lopes (2017) aponta que em países como Estados Unidos e Inglaterra os Estudos Surdos foram se constituindo na intersecção com outras áreas do conhecimento, no Brasil as pesquisas sobre os surdos aconteceram em diferentes campos do saber e por pesquisadores atravessados por diferentes perspectivas teóricas, no entanto, assim como em outros países duas grandes áreas de destacaram, quais sejam: educação e linguística.

\subsection{Perfil geral dos pesquisadores}

Optou-se por aglutinar os dados que utilizados para traçar o perfil geral dos pesquisadores envolvidos com a temática tratada, com pretensão de confrontar esses dados de fronte. O serviço público é o regime de contratação com mais pesquisadores, tendo como tipologiaas instituições de ensino e pesquisa. 
A similaridade entre os dois gráficos (regime de contratação e tipologia das instituições) não é mera coincidência; três dos autores que se identificaram como servidor público informaram também atuar profissionalmente em instituições de ensino e pesquisa, que são as mais citadas nas expectativas de atuação desses pesquisadores.

Quadro 3 - Conjunto de Gráficos sobre o perfil dos pesquisadores.

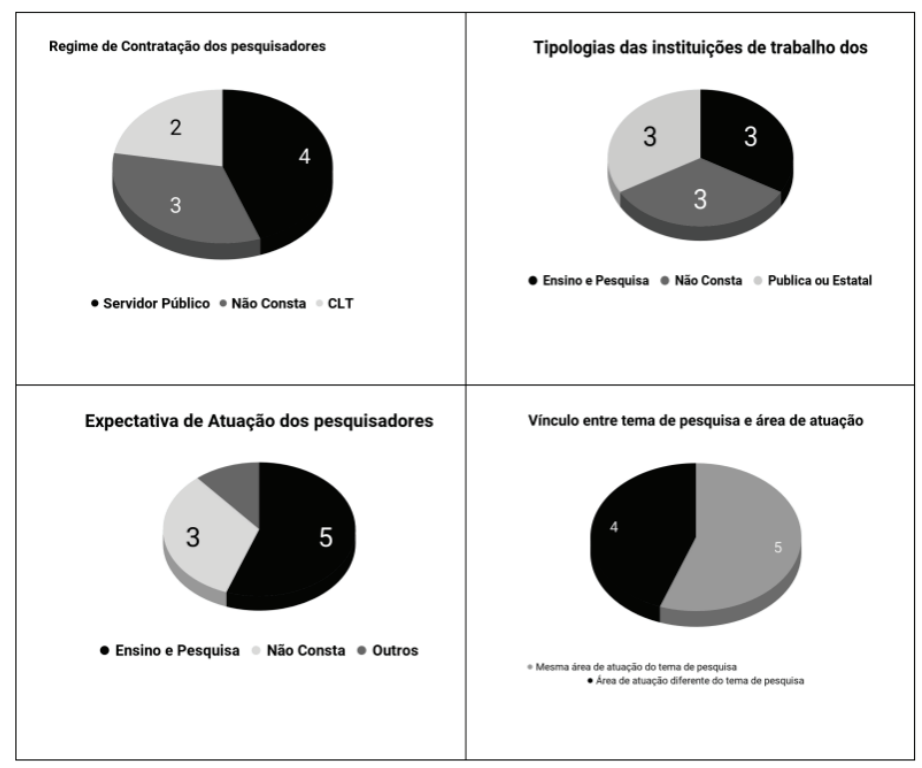

Fonte: Elaborado pela equipe de pesquisa.

$\mathrm{Na}$ relação entre as atividades laborais e o tema de suas pesquisas, embora a maior parte dos pesquisadores atue na mesma área de sua temática de investigação, a diferença do número de pesquisadores que não o fazem não é pequena. Assim reiterase que esse dado pode decorrer do aumento de interesses pela temática nos diversos campos de pesquisa.

\subsection{Temáticas abordadas nas pesquisas}

As duas pesquisas desenvolvidas em 2013 se remetem à formação docente. $O$ estudo [A] descreveu a formação docente dos professores do Ensino Fundamental II, que atendem alunos surdos no município de Porto Velho/RO, tendo em vista a perspectiva da inclusão de alunos surdos nas chamadas escolas regulares. De acordo com os achados do estudo, é preciso fortalecer a formação inicial e continuada dos professores, pois é precáriae não prepara o professor para atender o aluno surdo em suas especificidades; o aporte utilizado se pautou nos estudos sobre o Multiculturalismo Crítico, Estudos Culturais e Estudos Surdos, tendo os autores Canen e Moreira (2001) com contribuição de Reis (2013).

Já o estudo [B], também de 2013, buscou, desenvolvendo um projeto de extensão, apontar demandas, sugestões e propostas para uma formação teórica e prática de professores de surdos. Observou-se desalinho na descrição da referência das obras dos autores citados para fundamentar a noção interculturalidade neste estudo. De acordo com os relatos da pesquisa:

Maher (2007) e Cavalcanti (2007) definem interculturalidade como uma forma de manter a ideia da influência de culturas umas sobre as outras e na possibilidade de resistência aos conflitos culturais entre valores diferentes, considerando que o processo cultural implica dinamismo, transformação, reinterpretações. (SILVA, 2016, p.14).

Na lista de referências da referida dissertação não foi encontrada a apresentação da informação originada do documento e/ou outras fontes de informação referentes a obra 
de autoria de Cavalcanti $(2007)^{3}$ e para Maher $(2007)^{4}$ foram encontradas duas obras na lista de referência. Em suma, nas considerações é apontado que a educação dos alunos surdos poderia tornar-se mais sensível e mais relevante se fossem considerados os modos visuais deles aprenderem e se estivessem presentes nos contextos pedagógicos as demandas culturais e sociopolíticas (SILVA, M., 2013).

Conforme já informado, não foram encontrados trabalhos no ano de 2014; o ano de 2015 teve apenas uma pesquisa, [C], que analisou o processo de desenvolvimento da Competência Comunicativa Intercultural no ensino de língua estrangeira por meio de projetos colaborativos internacionais com uso de tecnologias digitais.

Partindo do entendimento de comunicador intercultural como o sujeito capaz de negociar conhecimento no encontro intercultural, ultrapassando os obstáculos que possam surgir, a avaliação da comunicação intercultural foi baseada na utilização dos vídeos de autoria dos próprios estudantes surdos. O respaldo teórico para as reflexões acerca da interculturalidade foi Byram (1997), Bennett M. (1998), Mendes (2011) e Candau (2012). Conforme as últimas considerações pela investigação, de acordo com a autorase pôde:

[...] concluir que os aprendizes, através da riqueza da interação, inerente ao desenvolvimento do projeto, e os vários recursos que foram colocados ao seu dispor, estabeleceram laços com os demais participantes, interlocutores de outras culturas, promovendo e ampliando a comunicação intercultural também localmente como conseqüência de pensar globalmente e agir localmente. (BATISTA, 2015, p. 76).

Entre as recomendações feitas pela pesquisadora, para designar os estudantes surdos que adquirem elevada Competência Comunicativa Intercultural, está a substituição do termo 'falante' por 'sinalizantes interculturais', justificado em prol do respeito à língua espaço-visual da pessoa surda. Para a autora o primeiro termonão se aplica aos surdos pois é usado para designar ouvinte na cultura surda (BATISTA, 2015).

Em 2016 também se encontrou apenas uma dissertação [D], que objetivou descrever e analisar o desenvolvimento linguístico e cognitivo de estudantes com implante coclear e usou como parâmetros as metodologias de ensino utilizadas pelo instituto Felipe Smaldone, em Belém. Os achados desta investigação indicam que:

(...) o ensino-aprendizagem de crianças com implante coclear é um processo que demanda práticas específicas e resultados de médio a longo prazo e, que, a habilitação auditiva por si só, não inclui esta criança no processo de escolarização ouvinte. (NAVEGANTES, 2016, p. 8).

A autora não emprega o termo interculturalidade e opta por circunscrever a perspectiva multicultural a partir de Santiago, Akkari e Marques (2013), segundo ela: "a perspectiva multicultural se configura em uma proposta de "educação para a alteridade" aos direitos do outro, à igualdade de oportunidades, uma proposta democrática mais ampla" (NAVEGANTES, 2016, p. 34). Observou-se, nas considerações finais, que a menção feita a Libras é singular, embora cite que tal língua precise ir para além do ensino de português, a argumentação retoma o foco instrumental da língua:

Em relação à Libras, vimos que as crianças surdas, inclusive as que usam IC, e que portanto são bilíngues, tem melhor desempenho no quesito das habilidades de compreensão auditiva.

(...) Em nosso entendimento, a Libras deve ser entendida como a língua de instrução desses alunos e não deverá ser tratada apenas como uma 'ponte' para a língua

\footnotetext{
3 As obras referentes a autoria "Cavalcanti" encontradas foram Cavalcanti (1999) e Cavalcanti (2006), com isso justificamos o fato de não haver na lista de referências dessa revisão obra correlata a Cavalcanti (2007).

4 A lista de referências da presente revisão de literatura utilizará Maher (2007a) e Maher (2007b) para designar as obras encontradas.
}

Cad. Pesq., São Luís, v. 26, n. 2, p. 169-193, abr./jun., 2019. 
portuguesa, apesar destes alunos com IC estarem se apropriando da linguagem oralizada. (NAVEGANTES, 2016, p. 113).

Atualmente estudiosos e pesquisadores do campo dos Estudos Surdos e da Educação de Surdos têm apontado que a necessidade está em valorizar a Libras comolíngua de conforto, de expressão, ou seja, como uma manifestação cultural do sujeito surdo que é produto e produz de subjetividades (STROBEL, 2015; PEIXOTO; DEJARDIN, 2016). Reiterando que, apesar de ter como descritor a palavra surdez, tal pesquisa tem como sujeitos os estudantes com implante coclear e que segundo a autora "[...] não seguem uma perspectiva bilíngue, e a orientação do Instituto é que seus professores procurem trabalhar com metodologias baseadas na oralização" (NAVEGANTES, 2016, p. 20), portanto, verificou-se que alguns perigos, como já alertado por Capovilla (2011), ao se discutir surdez e deficiência auditiva como sinônimos podem ser localizados quanto a definição da temática central.

Em 2017, ano que concentrou maior número de publicações, detectou-se novas temáticas sendo exploradas, por exemplo, o estudo, [E], que se desenvolveu no âmbito da educação inclusiva e teve como objetivo geral: validar o processo de internacionalização do currículo, na educação de surdos, pelos estágios e componentes de revisão/ reflexão e imaginação. Como objetivos específicos: definir a internacionalização, a interculturalidade; discutir a educação de surdos; sublinhar a cultura surda em sua relação com a cultura ouvinte; examinar o currículo, objeto do estudo, sob a perspectiva da internacionalização/interculturalidade e compor o estágio de imaginação do currículo objeto de estudo/ o lócus explorado é uma escola inclusiva (SANTIAGO, 2017). Os achados da pesquisadora reforçam a prerrogativa de que o espaço inclusivo não é o mais apropriado para o desenvolvimento do estudante surdo, pois apontam diversas lacunas na proposta pedagógica da escola estudada, no que diz respeito ao estudante surdo. Candau (2012) é a autora chamada para fundamentar a interculturalidade nesta pesquisa.

No mesmo ano, a pesquisa [F] se propôs a entrelaçar música, surdez e educação, tal estudo "se propõe, ainda, contribuir com os elementos interculturais do currículo, ampliando o conhecimento de mundo e levando ao sujeito informações sociais, a quem o acesso não ocorre de forma natural" (SILVA, A., 2017, p. 11). Sem reportarse a autores clássicos a pesquisa conceitua que "[...] o interculturalismo se apresenta como possível alternativa para o conflito entre surdos e ouvintes, descolonializando os saberes culturais de um grupo em detrimento do outro" (SILVA, A., 2017, p. 53). As considerações finais do autor apontam que "o som é compreensível para os surdos, uma vez que ele se materializa em vibrações sonoras, sentidas pela pele e também se apresenta no movimento dos corpos ouvintes" (SILVA, A., 2017, p. 109), com isso têm-se um indício de centralidade da perspectiva ouvintista sobre o sujeito surdo, visto que, é o corpo ouvinte que é destacado. Na mesma sessão, o autor cita ainda que "O surdo se apropria da música e passa a integrá-la como elemento cultural da sua cultura (...) a música, como elemento integrador do currículo na educação de surdos, é uma proposta que pretende oportunizar o ensino de conteúdos sem oprimir os estudantes" (SILVA, A., 2017, p. 109); nesse sentido, Oliveira (2014, p. 17) afirma que "A concepção de que música não faz parte da cultura surda é errônea", já autores como Perlin (1998), Perlin e Strobel (2014), Quadros (2006), Skliar (2013) e Strobel (2015) se mostram menos inclinados a aderir sem questionar esse tipo de afirmação. Logo, atualmente, não parece haver consenso estabelecido sobre o tema, no entanto, ambas perspectivas reconhecem a música como um elemento ainda externo à comunidade surda, portanto, artefato de conhecimento intercultural.

Outros dois trabalhos datados de 2017, debruçaram se sobre a etapa da Educação Infantil. Em [G] a teorização em torno da interculturalidade se apoiou em Moita Lopes (2006). O objetivo da pesquisa foi "descrever as interações no diálogo intercultural entre professores estagiários surdos, professoras regentes e crianças ouvintes em um contexto de ensino de LIBRAS como L2" (PRIETO, 2017, p. 59). A autora dá ênfase nas 
diferentes formas de significar a surdez e a aprendizagem de LIBRAS. Alguns achados são citados em suas últimas considerações:

\begin{abstract}
Pude perceber que no meio dessa complexa rede de interações iam se modelando papeis sociais e conscientizações perante a surdez, a LIBRAS e a prática pedagógica, transformando-as em cada encontro com o outro uma nova significação nesse processo de ensino aprendizagem. (...) Observou-se que os discursos iniciais da professora mais ligados à perspectiva oralista foram gradualmente modificados para uma conceição mais ligada a perspectiva sociocultural, a medida que se aproximava e apropriava da cultura surda e da língua de sinais por meio da interação social com os estagiários surdos. (PRIETO, 2017, p. 189).
\end{abstract}

Já em [H], o objetivo geral foi 'analisar as concepções de sujeito surdo, infância e educação subjacentes às políticas educacionais no cenário municipal e sua efetividade em relação ao direito à Libras como língua materna no contexto da educação infantil. A autora buscou aporte em alguns documentos oficiais e em Lucchesi (2008), segundo ela pelos resultados encontrados, confirma-se hipótese inicial da "hegemonia do modelo clínico-terapêutico na política educacional para a infância surda, em que a deficiência auditiva e sua reabilitação ocupa a centralidade da prática pedagógica" (NASCIMENTO, 2017, p. 169).

Por fim, ainda em 2017, o estudo [I] se propôs a "analisar a recente criação do cargo de professor intérprete de Libras em concurso público do município de Nova Iguaçu, no Estado do Rio de Janeiro" (COSTA, 2017, p. 16). Por meio de observações, análises de documentos e entrevistas - com professores intérpretes, professores regentes, orientadora educacional e demais profissionais de apoio pedagógico, nos estudo o autor chegou à conclusão de que, apesar da escola polo ainda não ter um quantitativo considerável de profissionais fluentes para ser considerada escola bilíngue, os professores intérpretes, professores regentes e professores da sala de recurso, por atuarem "de maneira conjunta, constroem possibilidades para que os alunos surdos participem do processo de ensino aprendizagem e avancem no processo de se tornarem sujeitos bilíngües" (COSTA, 2017, p. 18). A valorização do bilinguismo é uma discussão antiga, mas, que ainda merece espaço visto que os espaços destinados a estas práticas ainda se encontram sob ameaça (CAMPELLO; REZENDE, 2014).

Nenhuma das pesquisas aplicou métodos quantitativos. A metodologia mais empregada foi a qualitativa, no entanto, a inspiração etnográfica também aparece evidenciada:

Quadro 4 - Abordagem Metodológica das pesquisas

\begin{tabular}{|c|l|l|}
\hline Cod. & Descrição no Estudo & \multicolumn{1}{|c|}{ Métodos } \\
\hline A & $\begin{array}{l}\text { (...) com abordagem qualitativa, de cunho etnográfico e do tipo } \\
\text { descritiva (...) }\end{array}$ & Qualitativa / cunho etnográfico \\
\hline B & $\begin{array}{l}\text { (...)qualitativa/interpretativista, de cunho etnográfico, com sua orientação interdis- } \\
\text { ciplinar e multimetodológica }\end{array}$ & Qualitativa / cunho etnográfico \\
\hline C & (...) de cunho qualitativo (...) & Qualitativa \\
\hline D & (...) de cunho qualitativo (...) & Qualitativa \\
\hline E & Optamos por uma pesquisa qualitativa documental (...) & Qualitativa / Documental \\
\hline F & A metodologia se valeu de uma perspectiva político-cultural (...) & Perspectiva político-cultural \\
\hline G & Sendo uma pesquisa com fundamentos etnográficos (...) & Cunho etnográfico \\
\hline H & A abordagem metodológica de caráter qualitativo (...) & Qualitativa \\
\hline I & A pesquisa é de cunho qualitativo, na perspectiva teórica (...) & Qualitativa \\
\hline
\end{tabular}

Fonte: Elaborado pelos autores.

A tendência metodológica de dominância qualitativa é um dado que co-ocorre em pesquisas na área de Ciências Humanas, especialmente nas Ciências da Educação. 
É comum que se tenha em mente que a maior característica de uma pesquisa na área de Ciências Humanas é a compreensão, bem como, existe a crença de que só será possível compreender um dado fenômeno por meio da abordagem qualitativa. $\mathrm{Na}$ atualidade, autores diversos questionam essa crença (ALBRES; LACERDA, 2013; THESING; COSTAS, 2017)com abordagem qualitativa, sobre as ementas curriculares do curso em diferentes períodos (1984, 1987, 2004 e 2008.

\subsection{Fomento para os estudos}

De todas estas pesquisas apenas duas afirmaram ter fomento, [D] e [E]. O órgão de fomento de ambas foi a Capes. Ambas foram desenvolvidas em PPG de educação. A origem da pesquisa [D] é a capital do Rio de Janeiro. Já a da pesquisa [E] é Itajaí (SC).

Em suma, pode-se também dizer que as temáticas fomentadas foram internacionalização e implante coclear. A respeito da primeira, pode-se situar o ingresso das discussões sobre educação de surdos nas discussões em pauta na atualidade visto que a compreensão da construção cultural das identidades surdas é relevante para a compreensão dos conflitos entre as identidades surdas no contexto transnacional e global. A interação transnacional dos surdos fomentou a transferência de discursos (culturalmente construídos) sobre identidade surda, língua de sinais e cultura surda (BREIVIK, 2005; De CLERCK, 2007). A respeito da segunda temática, percebeu-se a persistência em um tópico polêmico, mas importante e que parece emergir na atualidade.

\section{ALGUMAS CONSIDERAÇÕES FINAIS}

Desenvolver um trabalho sistemático de revisão integrativa da literaturabrasileiras (dissertações e teses), entre os anos de 2013 e 2017, afinado com as tendências atuais de diversos campos do conhecimento, sobre as discussões que abordam interculturalidade na educação de surdos revelou alguns dados que nos deram condições decombinar apontamentos produzidos por distintas abordagens de investigação para atingir o objetivo geral de mapear a produção científica atual stricto sensu sobre interculturalidade e educação de surdos.Empreender em tal atividade pode ser uma proposta ousada visto que a RSL no campo da Educação, por não ter, ainda, uma tradição investigativa consolidada, pode oferecer constrangimentos porque se trata de um modelo de avaliação da literatura científica (FARIA, 2016).

A partir do corpus refinado, de nove estudos, pôde-se constatar a totalidade damodalidadedissertação. Embora tenha-se verificado uma tendência de crescimento em relação ao número de trabalhos ao longo dos últimos seis anos a inexistência de teses foi um achado preocupante, visto que as teses representam aprofundamento dos conhecimentos e inovação para o campo.Ainda sobre esse mesmo tópico, outro achado interessante foi de que o crescimento no interesse pelo campo da internacionalização da educação pode ter impulsionado as pesquisas no campo da interculturalidade, uma vez que a definição mais utilizada atualmente para discutir internacionalização prioriza os aspectos interculturais do processo.

A pesquisa expõe que os pesquisadores no Brasil têm cooperado para produzir conhecimento acerca da interculturalidade no espaço educacional. Em relação a educação de surdos, mais especificadamente, a formação de professores e os aspectos do desenvolvimento linguístico foram as temáticas mais exploradas. As discussões em torno da internacionalização e damúsica podem representar a ampliação das temáticas abordadas nos estudos sobre educação de surdos.

Sobre a abordagem da metodológica, embora as investigações analisadastratem de múltiplas temáticas dentro da interculturalidade na educação de surdos, há homogeneidade quanto ao aspecto qualitativo. Pesquisas de abordagem puramente quantitativa não foram encontradas em nenhum dos trabalhos, já as pesquisas qualitativas angariaram um montante de 90,5 \% das publicações. 
Ao aprofundar-se a análise de tais metodologias pôde-se perceber destaque entre a etnografia e o estudo de caso. Percebe-se também que existe muita discrepância com relação a descrição dos métodos. Alguns trabalhos não citavam com clareza tornando a análise dificultosa e por vezes inverossímil, no entanto admite-se a singularidade do trato metodológico no que tange as especificidades das Ciências Humanas.

A região sul do país se destacou no número de produções, esse fato pode ser explicado pela tradição dessa região em desenvolvimento de pesquisas na área da educação de surdos, bem como, por ser a segunda região que possuiu mais instituições com PPG no Brasil. Outro aspecto verificado sobre as instituições foram as categorias administrativas, aferiu-se quetodas as pesquisas foram desenvolvidas em PPG mantidos por instituições sem fins lucrativos.

O serviço público é o regime de contratação com mais pesquisadores. As instituições de ensino e pesquisa são as mais citadas em relação às expectativas de atuação dos pesquisadores. É também de uma instituição pública que o fomento para essas pesquisas foi concedido. Ressalta-se com isso a importância dos investimentos em pesquisasno campo da educação e em instituições sem fins lucrativos por parte do poder público.

As temáticas fomentadas foram internacionalização e implante coclear. Nesse sentido, salienta-se que é necessário mais fomento, para que as pesquisas possam alcançar mais temáticas, ou seja, há que se investir nas pesquisas dos diferentes assuntos atuais, porém sem deixar de dar a devida atenção às pesquisas que abordam temas já consolidados, afinal, nenhum conhecimento pode ser concluído ou acabado, pronto.

A metodologia aplicada se mostrou plenamente eficaz. O uso do protocolo de revisão facilitou a análise e inclusão/ exclusão de estudos. Cabe citar que a disposição dos trabalhos no portal da Capes facilitou imensamente a coleta dos dados para análise, apesar das limitações na estrutura da lógica de execução das strings e da extração dos dados.

\section{AGRADECIMENTOS}

Os autores agradecem ao professor Dr. Jefferson Seide Molléri por apresentar sugestões importantes incorporadas à pesquisa que auxiliaram na resolução de problemas fundamentais do trabalho.

\section{REFERÊNCIAS}

ALBRES, N. A.; LACERDA, C. B. F. de. Interpretação educacional como campo de pesquisa: estudo bibliométrico de publicações internacionais e suas marcas no campo nacional. Cadernos de Tradução, Florianópolis, v. 1, n. 31, p. 179-204, abr. 2013. Disponível em: <https:// periodicos.ufsc.br/index.php/traducao/article/view/2175-7968.2013v1n31p179>. Acesso em: 03 jun. 2018.

BATISTA, C. A. O desenvolvimento da competência comunicativa intercultural de surdos aprendizes de inglês: a internet como meio 23/07/2015 183 f. Mestrado em Lingüística Aplicada Instituição de Ensino: Universidade de Brasília, Brasília.

BAUMAN, H.-D. L. A mighty change: an anthology of deaf american writing 1816-1864 (review). Sign Language Studies, v. 2, n. 4, p. 452-459, Jan. 2002.

A review of deaf studies curricula. The Radical Teacher, n. 47, p. 25-26, 1995.

BAUMAN, H.-D. L.; DRAKE, J. Silence is not without voice: including deaf culture within multicultural curricula. In: DAVIS, L. J. (Ed.). The disability studies reader. New York: Routledge, 1997. 
BAUMAN, H.-D. L.; MURRAY, J. J. Deaf studies in the 21st century: "deaf-gain" and the future of human diversity. Oxford: Oxford University Press, 2010. Disponível em: <http://www. oxfordhandbooks.com/view/10.1093/oxfordhb/9780195390032.001.0001/oxfordhb9780195390032-e-014>. Acesso em: 03 jun. 2018.

BAUMAN, H.-D. L.; MURRAY, J. M. Reframing: from hearing loss to deaf gain. Deaf Studies Digital Journal, n. 1, p. 1-10, Sept. 2009.

BENNETT, J. M. (Ed.). The SAGE encyclopedia of intercultural competence. Thousand Oaks: SAGE Publications, 2015.

BENNETT, M. J. Intercultural communication: a current perspective. In: (Ed.). Basic concepts of intercultural communication: selected readings. Yarmouth-ME: Intercultural Press, 1998.

BOTELHO, L. L. R.; CUNHA, C. C. de A.; MACEDO, M. O método da revisão integrativa nos estudos organizacionais. Gestão e Sociedade, Belo Horizonte, v. 5, n. 11, p.121-136, maio/ ago. 2011. Disponível em: <http://www.gestaoesociedade.org/gestaoesociedade/article/ view/1220/906>. Acesso em: 03 jun. 2018.

BRANCO, A. P. S. C.; LEAL, D.; Inclusão de alunos surdocegos e a atuação de professores no ensino comum: revisão sistemática. Revista Educação Especial, Santa Maria-RS, v. 31, n. 61, p. 323-338, abr./jun. 2018. Disponível em: <https://periodicos.ufsm.br/educacaoespecial/ article/view/26295/pdf>. Acesso em: 03 jun. 2018.

BRANSON, J.; MILLER, D. Damned for their difference: the cultural construction of deaf people as disabled. Washington-DC: Gallaudet University Press, 2002.

BREIVIK, J.-K. Rome-a temporary deaf city!: deaflynicity in the United States. Sign Language Studies, 19, p. 139-152, 2005.

BYRAM, M. Ensinar e avaliar a competência comunicativa intercultural. Clevedon: Multilingual Matters, 1997.

CAMPELLO, A. R.; REZENDE, P. L. F. Em defesa da escola bilíngue para surdos: a história de lutas do movimento surdo brasileiro. Educar em Revista, Curitiba: Editora UFPR, n. 2, p. 71-92, 2014. Edição Especial. Disponível em: <http://www.scielo.br/pdf/er/nspe-2/06.pdf>. Acesso em: 03 jun. 2018.

CANDAU, V. M. F. Diferenças culturais, interculturalidade e educação em direitos humanos. Educação e Sociedade, Campinas, v. 33, n. 118, p. 235-250, jan./mar. 2012.

CANEN, A.; MOREIRA, A. F. B. Reflexões sobre o multiculturalismo na escola e na formação docente. In: (Org.). Ênfases e omissões no currículo. São Paulo: Papirus, 2001. p. $15-43$

CAPOVILLA, F. C. Sobre a falácia de tratar as crianças ouvintes como se fossem surdas, e as surdas, como se fossem ouvintes ou deficientes auditivas: pelo reconhecimento do status linguístico especial da população escolar surda. In: SÁ, Nídia Regina L. de. Surdos: qual escola? Manaus: Valer, 2011

CARVALHO, M. E. de; CAVALCANTI, W. M. A.; SILVA, J. A. da. Ensino de Língua Portuguesa para surdos: uma revisão integrativa da literatura. Revista CEFAC, São Paulo, v. 21, n. 5, 2019.

CAVALCANTI, M.C. Estudos sobre educação bilíngue e escolarização em contextos de minorias linguísticas no Brasil. Em: D.E.L.T.A., Vol. 15, N.o ESPECIAL, 1999, p. 385-417. 
M.C. Um olhar metateórico e metametodológico em pesquisa em Linguística Aplicada: implicações éticas e políticas. Em: MOITA LOPES, L.M. Por uma linguística Aplicada indisciplinar. São Paulo: Parábola, 2006.

COPPETE, M. C. Educação intercultural e sensibilidade: possibilidades para a docência. 2012. Tese (Doutorado em Educação)- Faculdade de Educação, Universidade Federal de Santa Catarina, Florianópolis, 2012.

CORREAA, Y.; GIOTTI, J.; CRUZ, C. R.; RIBEIRO, Vinicius G. Produção científica brasileira sobre tradução automática português brasileiro-libras: uma revisão sistemática de literatura. ReVEL, edição especial n. 15, 2018. [www.revel.inf.br].

COSTA, R. dos S. O professor intérprete de libras em uma escola polo do município de Nova Iguaçu. 2017. 154 f. Dissertação (Mestrado em Educação)- Faculdade de Educação, Universidade Federal do Rio de Janeiro, Rio de Janeiro, 2017.

COUTINHO, M. D. M. C.; CARVALHO, D. L. Educação matemática, surdez e letramentos: o processo de ensinar e aprender matemática mediado por duas línguas em contato. Revista Paranaense de Educação Matemática, Campo Mourão, v. 5, n. 9, p. 33-55, 2016.

De CLERCK, G. A. Meeting global deaf peers and visiting ideal deaf places: deaf ways of education leading to empowerment, an exploratory case study. American Annals of the Deaf, v. 152, n. 1, p. 5-19, 2007.

DESSBESEL, R. da S.; SILVA, S. de C. R. da; SHIMAZAKI, E. M. O processo de ensino e aprendizagem de matemática para alunos surdos: uma revisão sistemática. Ciência e Educação, Bauru, v. 24, n. 2, p. 481-500, abr. 2018. Disponível em: <http://www.scielo.br/ pdf/ciedu/v24n2/1516-7313-ciedu-24-02-0481.pdf>. Acesso em: 03 jun. 2018.

DRUMMOND, J. A. Anotações de um integrante de bancas examinadoras: teses e dissertações defendidas recentemente na área de Ciências Ambientais. Ambiente e Sociedade, Campinas, v. 5, n. 2, p. 191-214, 2003. Disponível em: <http://www.scielo.br/scielo.php?script=sci_ arttext\&pid=S1414-753X2003000200011>. Acesso em: 03 jun. 2018.

FARIA, P. M. Revisão sistemática da literatura: contributo para um novo paradigma investigativo. [S.I.]: Whitebooks. 2016. Edição do Kindle.

FELIZARDO, K. R. et al. Revisão sistemática da literatura em engenharia de software: teoria e prática. Rio de Janeiro: Elsevier, 2017.

FERREIRA, W. M.; NASCIMENTO, S. P. de F.; PITANGA, A. F. Dez anos da lei da LIBRAS: um conspecto dos estudos publicados nos últimos 10 anos nos anais das reuniões da Sociedade Brasileira de Química. Química Nova na Escola, São Paulo, v. 36, n. 3, p. 185-193, ago. 2014,

FLEURI, R. M. Intercultura e educação. Revista Brasileira de Educação, Rio de Janeiro, n. 23, p. 16-35, maio/ago. 2003.

M. Interculturalidade, identidade e decolonialidade: desafios políticos e educacionais. $\overline{R e v i s t a}$ Série-Estudos, Campo Grande-MS, n. 37, p. 89-106, jan./jul. 2014.

GAMBOA, S. Pesquisa em educação: métodos e epistemologias. 2. ed. Chapecó: Argos, 2012.

GOUGH, D.; THOMAS, J.; OLIVER, S. Clarifying differences between review designs and methods: systematic reviews. New York: [s.n.], 2012. 
KUSTERS, A. Since time immemorial until the end of days: an ethnographic study of the production of deaf space in Adamorobe, Ghana. United Kingdom: University of Bristol, 2012. $\mathrm{PhD}$ Thesis.

KUSTERS, A.; De MEULDER, M.; O'BRIEN, D. Innovations in deaf studies: critically mapping the field. In: _. (Ed.). Innovations in deaf studies: the role of deaf scholars. New York: Oxford University Press, 2017.

KUSTERS, A. M. J.; FRIEDNER, M. I. Introduction: deaf-same and difference in international deaf spaces and encounters. In: FRIEDNER, M.; KUSTERS, A. (Ed.). It's a small world: international deaf spaces and encounters. Washington-DC: Gallaudet University Press, 2015.

LADD, P. What is deafhood and why is it important? In: .GOODSTEIN, H. (Ed.). The deaf way II reader. perspectives from the second International Conference on Deaf Culture. Washington, DC: Gallaudet University Press, 2006. p. 245-50.

LADYMAN, J. (2002). Understanding Philosophy of Science. London: Routledge

LDB. Lei de diretrizes e bases da educação nacional. Brasília, DF: Senado Federal; Coordenação de Edições Técnicas, 2017. 58 p.

LEASK, Betty. Internationalizing the curriculum. New York: Routledge, 2015, 198p.

LEITE, B. S. Revisão sistemática sobre as produções científicas da Revista Tecnologias na Educação. Revista Tecnologias na Educação, ano 10, n. 25, p.1-16, jul. 2018.

LOPES, M. C.;. Professores Interlocutores e Educação de Surdos: a Inclusão na Rede Estadual Paulista. Rev. bras. educ. espec., Marília, v. 23, n. 4, p. 563-576, Dec. 2017 . Available from $<$ http://www.scielo.br/scielo.php?script=sci_arttext\&pid=S1413-65382017000400563\&lng=en \&nrm=iso>. access on 27 June 2019. http://dx.doi.org/10.1590/s1413-65382317000400007.

LOPES, M. C.; VEIGA-NETO, A. Acima de tudo, que a escola nos ensine: em defesa da escola de surdos. ETD - Educação Temática Digital, Campinas, v. 19, n. 4, p. 691-704, out./ dez. 2017. Disponível em: <https://doi.org/10.20396/etd.v19i4.8648637>. Acesso em: 03 jun. 2018.

LUCCHESI, D. Africanos, crioulos e a língua portuguesa. 2008. Disponível em: <www. coresmarcasefalas.pro.br/adm/anexos/10122008232732.pdf/>. Acesso em: 27 dez. 2011.

MACHADO, E. E.; TEIXEIRA, D. E.; GALASSO, B. J. B. Concepção do primeiro curso online de pedagogia em uma perspectiva bilíngue libras-português. Revista Brasileira de Educação Especial, Marília, v. 23, n. 1, p. 21-36, jan./mar. 2017.

MAHERa, T.J.M. A educação do entorno para a interculturalidade e o plurilinguismo. Em: KLEIMAN, A.B.; CAVALCANTI, M.C. (orgs.) Linguística Aplicada: suas faces e interfaces. Campinas: Mercado de Letras, 2007, p. 255-272.

MAHERb, T. J. M. Do casulo ao movimento: a suspensão das certezas na educação bilíngue e intercultural. In: CAVALCANTI, M.; BORTONI-RICARDO, S. M. (Org.). Transculturalidade, linguagem e educação. Campinas-SP: Mercado de Letras, 2007. p. 67-94.

MELO, L. B.; GOMES, M. J. As interações sociais dos surdos na internet: mapeamento sistemático da literatura. In: CONFERÊNCIA INTERNACIONAL DE TIC NA EDUCAÇÃO CHALLENGES, 8., 2013, Braga. Anais... Braga: Universidade do Minho, 2013. p. 1077-1091.

MENDES, E. (Org.). Diálogos interculturais: ensino e formação em português língua estrangeira. Campinas-SP: Pontes Editores, 2011. 310 p. 
MOITA LOPES, L. P. (Org.). Por uma lingüística aplicada indisciplinar. São Paulo: Parábola Editorial, 2006. 279 p.

MOROSINI, M.; FRANCO, M. E. D. P. Universidades comunitárias e sustentabilidade. Educar, Curitiba: Editora UFPR, n. 28, p. 55-70, 2004.

MUTTÃO, M.D.R.; LODI, A.C.B. Formação de professores e educação de surdos: revisão sistemática de teses e dissertações. Psicol. Esc. Educ., Maringá , v. 22, n. spe, p. 4956, 2018. Available from <http://www.scielo.br/scielo.php?script=sci_arttext\&pid=S1413$85572018000400049 \&$ lng $=e n \& n r m=i s o>$. access on 27 June 2019 . http://dx.doi. org/10.1590/2175-3539/2018/044.

NASCIMENTO, A. C. O direito a libras como língua materna: um estudo sobre a política educacional de educação infantil para crianças surdas na rede municipal de ensino de Curitiba. 2017. 127 f. Dissertação (Mestrado em Educação)- Universidade Federal do Paraná, Curitiba, 2017.

NAVENGANTES, E. V. Perceber, pensar e falar: o implante coclear na realidade escolar. 2016. 137 f. Dissertação. (Mestrado em Educação)- Faculdade de educação, Universidade Federal do Rio de Janeiro, Rio de Janeiro, 2016.

O'BRIEN, D.; STEAD, L.; NOURSE, N. Bristol deaf memories: archives, nostalgia and the loss of community space in the deaf community in Bristol. Social \& Cultural Geography, p. 1-19, 2017. Disponível em: <https://www.tandfonline.com/doi/full/10.1080/14649365.2017.1392591 >. Acesso em: 26 mar. 2018.

OHNA, S. E. Open your eyes: deaf studies talking. Scandinavian Journal of Disability Research, v. 12, n. 2, p. 141-146, 2010.

OLIVEIRA, H. C. da C. O desenvolvimento do sujeito surdo a partir da música. Revista Virtual da Cultura Surda, Petrópolis: Editora Arara Azul, n. 14, set. 2014.

PADDEN, C.; HUMPHRIES, T. Deaf in America: voices from a culture. Cambridge-MA: Harvard University Press, 1988. Disponível em: <https://books.google.com.br/books?id=FLdCukOYekgC \&printsec $=$ frontcover\&hl=pt-BR\&source $=g b s \_V i e w A P I \& r e d i r \_e s c=y \# v=0 n e p a g e \& q \& f=f a l s e>$. Acesso em: 26 mar. 2018.

PEIXOTO, J.L.B.; DEJARDIN, I. P. Um olhar multirreferencial para pesquisas em espaços escolares. In: Dante Augusto Galeffi; Maria A. C. Tourinho;Maria R. G. Sá. (Org.). Educação e Difusão do Conhecimento: caminhos da formação. 1ed.Salvador: EDUNEB, 2016, v. 1, p. 457-486.

PEREIRA, Aldo. (2017). Revisão Sistemática da Literatura: Como Escrever um Artigo Científico em 72 Horas. Rio de Janeiro, RJ: Edição do autor, 2017. 100 p. ISBN: 978-85922461-4-3 1. eBook Kindle.

PERLIN, G. T. T. Identidades surdas. In: SKILIAR, C. (Org.). A surdez: um olhar sobre as diferenças. Porto Alegre: Mediação, 1998.

PERLIN, G.; STROBEL, K. História cultural dos surdos: desafio contemporâneo. Educar em Revista, Curitiba: Editora UFPR, v. 30, n. 2, p. 17-31, 2014. Edição especial. Disponível em: <https://revistas.ufpr.br/educar/article/view/37011/23089>. Acesso em: 26 mar. 2018.

PRIETO, A. G. Interações interculturais no contexto de ensino de libras como L2 na creche. 2017. 242 f. Dissertação (Mestrado em Linguística)- Universidade Federal de Santa Catarina, Florianópolis, 2017. 
QUADROS, R. Políticas lingüísticas e educação de surdos em Santa Catarina: espaço de negociações. Cadernos CEDES, Campinas, v. 69, p. 141-162, 2006.

RAMOS, A., FARIA P. M., FARIA, Á. (2014). Revisão sistemática de literatura: contributo para a inovação na investigação em Ciências da Educação. Rev. Diálogo Educ., Curitiba, v. 14, n. 41, p. 17-36, jan./abr. Curitiba: Brasil doi: 10.7213/dialogo.educ.14.041.DS01

REIS, D. S. Formação docente e educação de surdos: um encontro com a diferença, cultura e identidade surda. 2013. 147f. Dissertação (Mestrado em Educação)- Universidade Federal de Rondônia, Porto Velho, 2013.

ROCHA, P. S. R.; LIMA, R. W. de; QUEIROZ, P. G. G. Tecnologias para o ensino da Língua Brasileira de Sinais (LIBRAS): uma revisão sistemática da literatura. Revista Brasileira de Informática na Educação - RBIE, v. 26, n. 3, p. 42-60, 2018.

SÁ, N. R. L. Cultura, poder e educação de surdos. São Paulo: Paulinas, 2006.

SANTIAGO, M. C.; AKKARI, A.; MARQUES, L. P. Educação intercultural: desafios e possibilidades. Petrópolis-RJ: Vozes, 2013.

SANTIAGO, V. de N. A educação de surdos pelos estágios do processo de internacionalização do currículo. 2017. 124 f. Dissertação (Mestrado em Educação)- Universidade do Vale do Itajaí, Itajaí, 2017.

SANTOS, B. de S. Para uma sociologia das ausências e uma sociologia das emergências. Revista Crítica de Ciências Sociais, n. 63, p. 237-280, out. 2002.

SAUR-AMARAL, I. (2011) Towards a Methodology for Literature Reviews in Social Sciences. Investigação e Intervenção em Recursos Humanos - gestão para a cidadania, Porto.

SILVA, A. M. Tradução de música \& educação de surdos. 2017. 126 f. Dissertação (Mestrado Acadêmico em Letras)- Universidade Federal de Rondônia, Porto Velho, 2017.

SILVA, L. B. Inclusão de alunos surdos na Escola Municipal de Ensino Fundamental João Moreira Soares. 2011. 24 f. Trabalho de Conclusão de Curso (Curso de Especialização em Gestão Pública Municipal)- Universidade Federal da Paraíba, João Pessoa, 2011.

SILVA, M. de F. da. Educação intercultural bilíngue para surdos: formação do professor para um ensino culturalmente sensível/relevante. 2013. 96 f. Dissertação (Mestrado em Sociedade Cultura e Fronteira)- Universidade Estadual do Oeste do Paraná, Cascavel, 2013.

SILVA, T. T. da. Documentos de identidade: uma introdução às teorias do currículo. 3. ed. Belo Horizonte: Autêntica, 2009.

SKLIAR, C. A surdez: um olhar sobre as diferenças. 6. ed. Porto Alegre: Mediação, 2013.

STROBEL, K. As imagens do outro sobre a cultura surda. 3. ed. rev. Florianópolis: Ed. da UFSC, 2015.

THESING, M. L. C.; COSTAS, F. A. T. A pesquisa em educação aproximações iniciais. Revista Ibero-Americana de Estudos em Educação, v. 12, n. 3, p. 1839-1853, jul./set. 2017.

TRANFIEL,D.;DENYER, D. SMART, P. (2003). Towards a methodology for developing evidence-informed management knowledge by means of systematic review. British Journal of Management, 14(3), P. 207-222. 
TRANFIEL, D.; MOUCHEL, D. (2002). Developing an evidence-based approach to management knowledge using systematic review: Advanced Management Research Centre, Cranfield School of Management. DOI: 10.1590/s1413-65382317000400007.

TRENCHE, M. C. B. A criança surda e a linguagem no contexto escolar. 1995. Tese (Doutorado em História e Filosofia da Educação)- Pontifícia Universidade Católica de São Paulo, São Paulo, 1995.

VERTUAN, G. de S.; SANTOS, L. F. dos. O ensino de química para alunos surdos: uma revisão sistemática. Revista Educação Especial, Santa Maria, v. 32, 2019. Disponível em: <https://periodicos.ufsm.br/educacaoespecial>. Acesso em: 03 maio 2019.

WALSH, C. Interculturalidade critica: pedagogia decolonial. Revista de Educação Técnica e Tecnológica em Ciências Agrícolas, v. 3, n. 6, p. 25-42, dez. 2012. Disponível em: <http://www. ufrrj.br/SEER/index.php?journal=retta\&page $=$ article\&op=view\&path $\% 5 B \% 5 D=1071>$. Acesso em: 03 maio 2019.

WHITTEMORE, R.; KNAFL, K. The integrative review: updated methodology. Journal Advanced Nursing, v. 52, n. 5, p. 546-53, Dec. 2005.

WRIGLEY, O. The politics of deafness. Washington: Gallaudet University Press, 1996.

YOUNG, A.; TEMPLE, B. Approaches to social research: the case of deaf studies. [S.I.]: Oxford University Press, 2014. 